\title{
Intermittent Theta-Burst Transcranial Magnetic Stimulation Alters Electrical Properties of Fast-Spiking Neocortical Interneurons in an Age-Dependent Fashion
}

\section{OPEN ACCESS}

Edited by:

Alexander Rotenberg, Boston Children's Hospital and Harvard Medical School, USA

Reviewed by: Vatsala Thirumalai, National Centre for Biological

Sciences, India Ya-tang Li, California Institute of Technology, USA

*Correspondence: Klaus Funke klaus.funke@rub.de

Received: 14 December 2015 Accepted: 13 March 2016 Published: 30 March 2016

Citation:

Hoppenrath K, Härtig W and Funke K (2016) Intermittent Theta-Burst Transcranial Magnetic Stimulation Alters Electrical Properties of Fast-Spiking Neocortical Interneurons in an Age-Dependent Fashion. Front. Neural Circuits 10:22. doi: 10.3389/fncir.2016.00022

\author{
Kathrin Hoppenrath ${ }^{1,2}$, Wolfgang Härtig ${ }^{3}$ and Klaus Funke ${ }^{1 *}$ \\ ${ }^{1}$ Department of Neurophysiology, Medical Faculty, Ruhr-University Bochum, Bochum, Germany, ${ }^{2}$ Rottendorf Pharma \\ GmbH, Ennigerloh, Germany, ${ }^{3}$ Pathophysiology of Neuroglia, Paul Flechsig Institute for Brain Research, University of Leipzig, \\ Leipzig, Germany
}

Modulation of human cortical excitability by repetitive transcranial magnetic stimulation (rTMS) appears to be in part related to changed activity of inhibitory systems. Our own studies showed that intermittent theta-burst stimulation (iTBS) applied via rTMS to rat cortex primarily affects the parvalbumin-expressing (PV) fast-spiking interneurons (FSIs), evident via a strongly reduced PV expression. We further found the iTBS effect on PV to be age-dependent since no reduction in PV could be induced before the perineuronal nets (PNNs) of FSls start to grow around postnatal day (PD) 30. To elucidate possible iTBS-induced changes in the electrical properties of FSls and cortical network activity during cortical critical period, we performed ex vivo-in vitro whole-cell patch clamp recordings from pre-labeled FSls in the current study. FSIs of verum iTBS-treated rats displayed a higher excitability than sham-treated controls at PD29-38, evident as higher rates of induced action potential firing at low current injections (100-200 pA) and a more depolarized resting membrane potential. This effect was absent in younger (PD26-28) and older animals (PD40-62). Slices of verum iTBS-treated rats further showed higher rates of spontaneous excitatory postsynaptic currents (sEPSCs). Based on these and previous findings we conclude that FSIs are particularly sensitive to TBS during early cortical development, when FSls show an activity-driven step of maturation which is paralleled by intense growth of the PNNs and subsequent closure of the cortical critical period. Although to be proven further, rTMS may be a possible early intervention to compensate for hypo-activity related mal-development of cortical neuronal circuits.

Keywords: repetitive transcranial magnetic stimulation, cortical fast spiking interneurons, parvalbumin, calciumbinding protein, development

\footnotetext{
Abbreviations: ACSF, artificial cerebrospinal fluid; BDNF, brain-derived neurotrophic factor; Cy3-WFA, Wisteria floribunda agglutinin conjugated to carbocyanine 3; EGTA, ethylene glycol tetraacetic acid; FSIs, fast-spiking interneurons; GAD67, 67kD isoform of glutamic acid decarboxylase; iTBS, intermittent theta-burst stimulation; LTD, LTP, long-term depression/potentiation; PBS, phosphate buffered saline; PD, postnatal day; PNNs, perineuronal nets; PV, parvalbumin PTX, picrotoxin; QX-314, (N-Ethyllidocaine chloride); rTMS, repetitive transcranial magnetic stimulation; TMS, transcranial magnetic stimulation.
} 


\section{INTRODUCTION}

Due to its modulatory action on human cortical excitability, repetitive transcranial magnetic stimulation (rTMS) has become a promising tool for the treatment of psychiatric and neurodegenerative disorders and cortical reorganization after stroke (Di Lazzaro et al., 2008a; Grefkes et al., 2010; Fitzgerald, 2011; for review, see Lefaucheur et al., 2014). However, little is known about the cellular mechanisms and network effects fundamental to the rTMS-induced changes in cortical excitability, a matter which appears as a prerequisite for optimizing the therapeutic potential of rTMS. The direction of change in cortical excitability primarily depends on stimulation frequency, with low frequencies $(<5 \mathrm{~Hz})$ being suppressive but higher frequencies being facilitative. Also the temporal structure of stimulation seems to be an effective parameter because raised cortical excitability is primarily found with intermittent stimulation, e.g., intermittent theta-burst stimulation (iTBS), while a single uninterrupted train (continuous TBS) tends to suppress cortical excitability (Huang et al., 2005). Besides possible induction of long-term depression (LTD)- and long-term potential (LTP)-like changes in cortical synaptic connectivity directly induced by low- and high-frequency stimulation protocols (Thickbroom, 2007), also a modulation of the activity of inhibitory cortical systems has been discussed on the basis of human data (Di Lazzaro et al., 2008b; Rogasch et al., 2014). By applying different rTMS protocols to rats, we could recently show that neuronal activity markers related to GABAergic neurons, like the $67 \mathrm{kD}$ isoform of GABA synthesizing enzyme glutamic acid decarboxylase (GAD67) and the calcium-binding proteins parvalbumin $(\mathrm{PV})$ and calbindin expressed in different classes of inhibitory interneurons (Kawaguchi and Kubota, 1998; Kawaguchi and Kondo, 2002; Markram et al., 2004), are differently affected by low- $(1 \mathrm{~Hz})$ and high-frequency (iTBS, cTBS) protocols and that particularly the iTBS protocol induces a strong and reliable reduction in the number of cells expressing PV within about $30 \mathrm{~min}$ (Trippe et al., 2009; Benali et al., 2011; Hoppenrath and Funke, 2013; Volz et al., 2013; Mix et al., 2014).

Neuropsychiatric disorders are discussed as being partly associated with a malfunction of inhibitory cortical systems, either as a result of acute interventions like abuse of drugs affecting glutamatergic transmission via NMDA receptors (Taylor and Tso, 2015) or as a result of prenatal disturbance of the development of inhibitory (cortical) systems (Selemon and Zecevic, 2015). In particular the number of interneurons expressing the calcium-binding protein $\mathrm{PV}$ is strongly decreased in patients with schizophrenic background (Beasley and Reynolds, 1997; Beasley et al., 2002; Lewis et al., 2005), accompanied by a diminished level of GAD67 (Knable et al., 2002; Hashimoto et al., 2003). Moreover, chondroitin sulfate proteoglycan-rich, polyanionic perineuronal nets (PNNs; Brückner et al., 1993) known to frequently surround $\mathrm{PV}^{+}$ interneurons (Härtig et al., 1992) are diminished in adolescents suffering from schizophrenia, indicating a discontinuous maturation of PNNs (Mauney et al., 2013). PNNs were recently discussed to be neuroprotective (Suttkus et al., 2016) and essential for long-term memory (Tsien, 2013). During neonatal cortical development $\mathrm{PV}^{+}$fast-spiking interneurons (FSIs) play an important role in the activity-dependent finetuning of thalamocortical and some corticocortical synaptic connections-for example, $\mathrm{PV}^{+}$interneurons are required for precise orientation tuning and binocular integration of sensory signals within the primary visual cortex (for review see Hensch, 2005). A manipulation of the sensory input like with dark-rearing or monocular deprivation in case of the visual system, or a pharmacological manipulation of the activity of the cortical inhibitory systems during this early cortical critical period considerably disturbs this process with longlasting consequences in visual performance as known for amblyopia (Jefferis et al., 2015). Also prenatal disturbance of the development of inhibitory neurons may thus affect the plasticity processes of the cortical critical period and it would be of great advantage if this process could be positively affected by interventions like non-invasive brain stimulation.

In two recent studies, we already tested how iTBS, the protocol that strongly reduced the PV expression (40-50\% reduction in the number of $\mathrm{PV}^{+}$cells), affects the rat cortex when applied during the cortical critical period. Firstly, we found that the iTBS-induced decrease in PV expression could not be induced before postnatal day (PD) 30 but steeply increased between PD32 and PD37, paralleled by a strong burst of growth of the PNNs (Mix et al., 2015). This finding indicates that $\mathrm{PV}^{+}$FSIs interneurons have to attain a distinct developmental state reached just during the critical period to respond to the stimulation. Secondly, we could show that iTBS applied during the critical period to dark-reared rats can prevent the loss of visual performance, obviously by enhancing the cortical brain-derived neurotrophic factor (BDNF) level in an activity-dependent fashion (Castillo-Padilla and Funke, 2016) that had been lowered by dark-rearing (Fagiolini et al., 1994). The current study was focused on the question whether $\mathrm{PV}^{+}$interneurons respond to iTBS in an age-dependent fashion also by electrophysiological aspects. Therefore, we performed whole-cell in vitro patch-clamp recordings from pre-labeled FSIs of 26-62 days old rats to test them for changes in electrophysiological cell membrane properties and excitability, and further recorded spontaneous postsynaptic potentials to estimate changes in cortical network excitability.

\section{MATERIALS AND METHODS}

\section{Animals}

Eighty-one male Sprague Dawley rats (Janvier, Genest-St-Isle, France) of different postnatal age (PD-postnatal day) were used in this study. Animals were kept in a $12 \mathrm{~h}$ day/night cycle (light on at 8:00 am) and had free access to food pellets and water. Rats increased in weight from about $50 \mathrm{~g}$ at PD26 to about $220 \mathrm{~g}$ at PD62. All animal experiments were performed with the permission of the government (AZ. 87-51.04.2010.A097) and the local animal welfare committee. All procedures complied with 


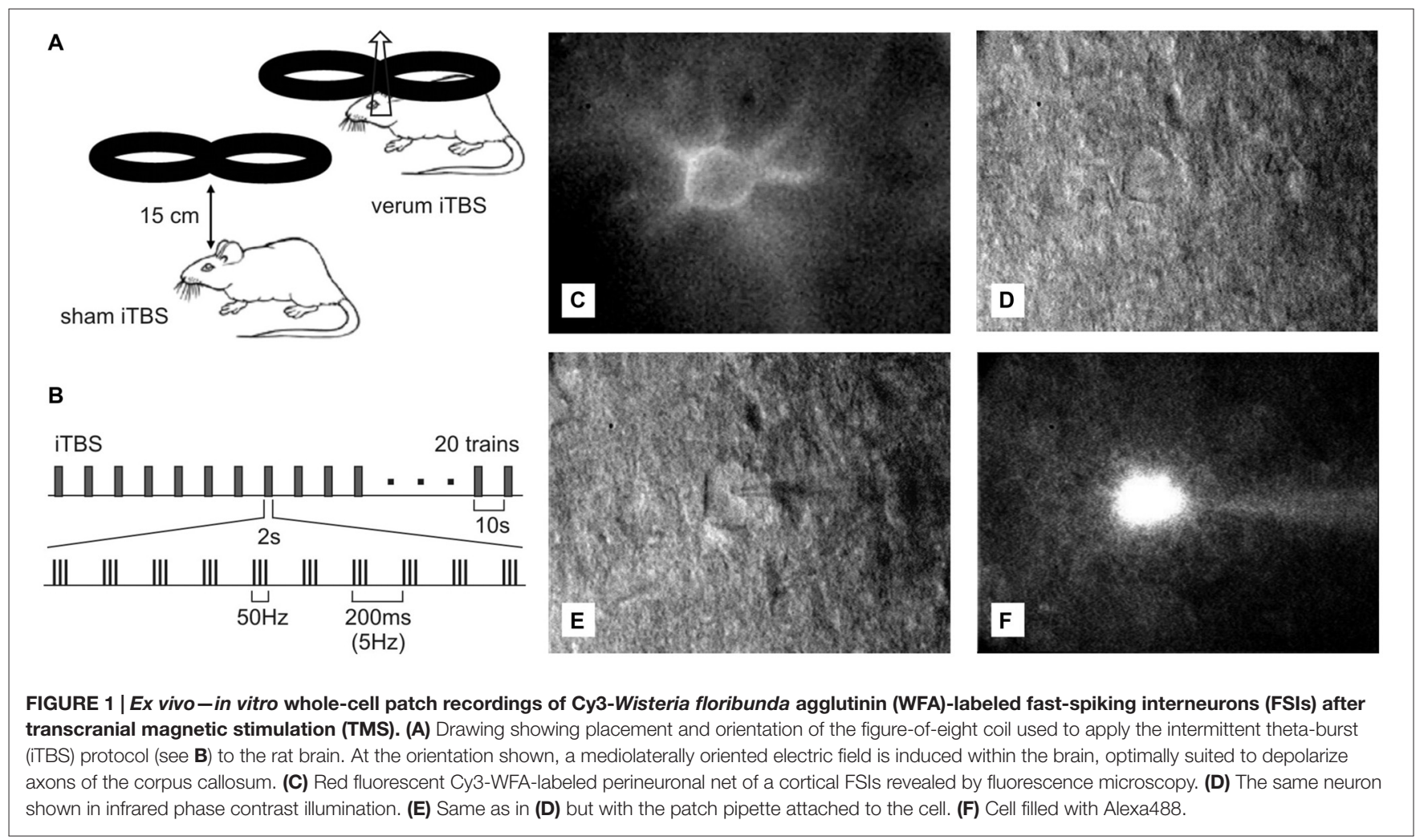

the guidelines of the animal welfare laws in Germany and the European Union.

\section{rTMS}

As in previous studies (Mix et al., 2010; Hoppenrath and Funke, 2013), rTMS was applied to conscious rats which had been familiarized to the stimulation procedure during the week prior to sham or verum stimulation. Rats were trained to tolerate the manual restraint and the noise and skin sensations (tingling) related to the rTMS procedure to avoid effects due to acute stress. The animal's body was kept with both hands and with the index fingers flanking the head to achieve a stable head-tocoil position. Food rewards served as positive reinforcements. According to previous experiments (Mix et al., 2010, 2015; Hoppenrath and Funke, 2013), rTMS was applied below motor threshold (threshold to induce motor responses) using $23 \%$ of maximal machine power. Stimuli were generated with a MagStim rapid ${ }^{2}$ magnetic stimulator (The MagStim Company, Whitland, Dyfed, UK) and applied via a conventional $70 \mathrm{~mm}$ figure-of-eight coil positioned tangential to the dorsal surface of the rat's head at a distance of about $8 \mathrm{~mm}$ in case of verum stimulation but $150 \mathrm{~mm}$ in case of sham stimulation. Direct coilto-skin contact was avoided and the absolute distance between head and coil was slightly adjusted to just prevent muscle twitches. As previously described, we used a coil orientation capable of inducing a mediolaterally oriented electric field within the brain, suitable to activate primarily axons of the corpus callosum but less other structures of the brain directly (see Benali et al., 2011; Mix et al., 2015). Thereby, we likely achieved synaptic activity in cortical layers $2 / 3$ via the axon collaterals of callosal axons, suitable to mimic activation patterns in human cortex. Each animal received a total number of 1800 pulses iTBS, applied as three blocks of the conventional iTBS protocol (Huang et al., 2005) separated by 15 min (Nettekoven et al., 2014). One iTBS block consisted of 20 trains with each train including 10 bursts of three pulses at $50 \mathrm{~Hz}$ which were repeated at $5 \mathrm{~Hz}$. Each trains lasted $2 \mathrm{~s}$ and was repeated at $10 \mathrm{~s}$ intervals, summing up to a total block length of $192 \mathrm{~s}$ (see also Figures 1A,B).

\section{Slice Preparation}

Brain slices including the somatosensory cortex were prepared as frontal sections (SC, $1.8 \mathrm{mM}$ posterior to bregma, $290 \mu \mathrm{m}$ thick). One hour after the last iTBS block rats were deeply anesthetized with carbon dioxide and killed by decapitation. The brains were quickly removed and stored in ice-cold artificial cerebrospinal fluid (ACSF). Six coronal slices were prepared from each brain using a vibratome (VT 1000S, Leica, Wetzlar, Germany). Slices obtained from animals up to PD38 were incubated in ACSF containing: $\mathrm{NaCl} 125 \mathrm{mM}, \mathrm{KCl} 3 \mathrm{mM}$, $\mathrm{NaHCO}_{3} 26 \mathrm{mM}, \mathrm{CaCl}_{2} 2.5 \mathrm{mM}, \mathrm{MgSO}_{4} 1.3 \mathrm{mM}, \mathrm{NaH}_{2} \mathrm{PO}_{4}$ $1.25 \mathrm{mM}$, D-glucose $13 \mathrm{mM}, \mathrm{pH} 7.4$, continuously oxygenated with carbogen $\left(95 \% \mathrm{O}_{2}, 5 \% \mathrm{CO}_{2}\right)$. Sections from animals older than 40 days were incubated in a cutting solution containing a somewhat different composition of substances to prevent excitotoxicity: $\mathrm{NaCl} 87 \mathrm{mM}, \mathrm{NaHCO}_{3} 26 \mathrm{mM}$, D-glucose $10 \mathrm{mM}$, sucrose $75 \mathrm{mM}$, $\mathrm{KCl} 2.5 \mathrm{mM}, \mathrm{NaH}_{2} \mathrm{PO}_{4}$ $1.25 \mathrm{mM}, \mathrm{CaCl}_{2} 0.5 \mathrm{mM}, \mathrm{MgSO}_{4} 3.5 \mathrm{mM}, \mathrm{pH}$ 7.4. All slices 
were kept in oxygenated ACSF for at least $30 \mathrm{~min}$ at $30^{\circ} \mathrm{C}$ before recording. To label PNNs surrounding PV expressing FSI in the living brain slice, $20 \mu \mathrm{l}$ of Cy3-tagged Wisteria floribunda agglutinin (WFA; $1.8-2 \mathrm{mg} / \mathrm{ml}$; prepared according to Brückner et al., 1996) was added to $2 \mathrm{ml} \mathrm{ACSF}$, and with the brain slices incubated for up to $1 \mathrm{~h}$ at room temperature under continuous oxygenation. In pilot experiments, with variations in the concentration of Cy3-WFA, incubation time and temperature, and in comparison to bolus injections into the slice, we found these settings to be most effective for sufficiently labeling the PNNs of FSIs within $1 \mathrm{~h}$ and devoid of high levels of background staining. Next, single slices were transferred to the recording chamber, mounted on an upright epifluorescence microscope (OLYMPUS-BX51-WI, Olympus Deutschland $\mathrm{GmbH}$, Hamburg, Germany) equipped with a $4 \times$ and a $40 \times$ water immersion objective. The recording chamber was steadily perfused at a rate of $1.25 \mathrm{ml} / \mathrm{min}$ with oxygenated $\mathrm{ACSF}$ of $33^{\circ} \mathrm{C}$.

\section{Electrophysiological Recordings and Data Analysis}

Patch electrodes were prepared from $1.5 \mathrm{mM}$ borosilicate glass capillaries (GB 150F-8P, Science Products GmbH, Germany) using a horizontal puller (P-1000, Sutter Instruments Co., Novata, CA, USA) with settings resulting in 6-9 $\mathrm{M} \Omega$ total impedance. The potassium-based internal solution contained Alexa488 hydrazide (100 $\mu \mathrm{M}$, Molecular Probes, Eugene, TX, USA) dissolved in the following mixture (in $\mathrm{mM}$ ): K-gluconate 97.5, $\mathrm{KCl} 32.5$, HEPES 10, $\mathrm{MgCl}_{2}$ 1, $\mathrm{Na}_{2}$ ATP 4, EGTA (ethylene glycol tetraacetic acid) 5, at $\mathrm{pH} 7.3$ (adjusted with $\mathrm{KOH}$ ). In case of measuring postsynaptic currents, $5 \mathrm{mM}$ QX-314 chloride (N-Ethyllidocaine chloride) was added to the pipette solution to prevent action potentials by blocking the voltageactivated sodium channels. Cy3-WFA-labeled interneurons were visualized and detected using epifluorescence illumination in combination with infrared-differential interference contrast (IR-DIC) microscopy (see Figures 1C-F) and a filter setting suitable for detection of $\mathrm{Cy} 3$ and Alexa488 fluorescence. Single cell responses obtained with whole-cell patch clamp recordings were amplified using a PC-501A amplifier (Warner Instruments, Hamden, CT, USA), recorded and digitized at a sampling frequency of $2.73 \mathrm{kHz}$ using WinWCP Software (version 4.6.7, Strathclyde University, Scotland) and a Digidata 1440A interface (Axon CNS, Molecular Devices, Sunnyvale, CA, USA) before being finally stored on a hard disk for off-line analysis. Since rTMS effects fade with time, we applied whole-cell patch recordings instead of perforated patch recordings because the latter require a further equilibration phase of 30-40 min until the number of gramicidine pores stabilizes. To minimize dilution of cytoplasmatic $\mathrm{PV}$ with pipette solution, recordings were kept as short as possible $(\sim 10 \mathrm{~min})$ by measuring current injection induced action potential firing and spontaneous synaptic currents in different cells. Thereafter, patch-clamps were directly terminated for analysis another cell in the same or a different slice. Unfortunately, this procedure of short whole-cell patch recordings yielded most cells insufficiently stained with Alexa488 for histological verification.

After the whole-cell configuration had been achieved in voltage clamp mode, 10 voltage pulses of $100 \mathrm{~ms}$ duration $(-100 \mathrm{mV}$ to $-10 \mathrm{mV}$ at steps of $10 \mathrm{mV})$ originating from a holding potential of $-60 \mathrm{mV}$ were applied to obtain input resistance, time constant and capacitance of the cell membrane from the current-voltage relationships. Subsequently, while in current clamp mode, somatic currents of $-50 \mathrm{pA}$ to $+115 \mathrm{pA}$ and $100 \mathrm{~ms}$ duration were injected to reveal membrane resting potential (MRP) and input resistance. A depolarizing current ramp of $1 \mathrm{mV} / \mathrm{ms}$ induced by $80 \mathrm{pA}$ current injection was used to evoke action potentials and to determine the threshold of action potentials. In order to analyze evoked spike firing, five different depolarizing current steps (100-500 pA, step size 100 pA) were injected for $1 \mathrm{~s}$ into one sample of cells. Data were analyzed as spiking frequency vs. injected current plots. Measurements of spontaneous postsynaptic currents (sPSCs) were done in a separate sample of cells at $-80 \mathrm{mV}$ holding potential during five recording episodes of $2 \mathrm{~s}$ each. Measurements were performed twice, without and with $100 \mu \mathrm{M}$ picrotoxin (PTX, Tocris) added to the bath solution to block $\mathrm{GABA}_{\mathrm{A}}$ receptor mediated spontaneous inhibitory postsynaptic currents (sIPSCs), while leaving the spontaneous excitatory postsynaptic currents (sEPSCs) unaffected. For detection and analysis of sPSCs, we used WinEDR Software (Strathclyde University, Glasgow, UK) and Mini Analysis Software (Synaptosoft Inc. Decatur, GA, USA). Threshold for sPSC detection was set to 2-times the standard deviation of noise amplitude and further parameters like initial rise in sPSCs and duration were adjusted for optimal sPSC detection under visual inspection using Mini Analysis software. sPSCs resulting from temporal summation of sPSCs were also manually excluded from the statistical analysis. In addition, WinWCP (Strathclyde University) and Clampfit 10.2 (Axon Instruments, Molecular Devices, Sunnyvale, CA, USA) Software were utilized for recordings and data analyses. Generally, one cell was studied per slice if measurements were successful and slices were refused if no stable whole cell patchclamp recordings could be achieved within $1 \mathrm{~h}$ after Cy3-WFA pre-labeling.

\section{Histochemical Analysis}

Following electrophysiology brain slices were transferred to $4 \%$ paraformaldehyde for $48 \mathrm{~h}$. After cryoprotection in $30 \%$ sucrose for 3 days, $30 \mu \mathrm{m}$ thick coronal cryosections (parallel to brain slice surfaces) were prepared and directly mounted on slides for visual inspection in a fluorescence microscope (Leitz Wetzlar Dialux 20 microscope; Leica, Solms, Germany). Sections containing Alexa488 stained cells were then used for immunohistochemical staining of PV while the PNNs were labeled with Cy3-conjugated Cy3-WFA. After a first washing procedure using phosphate buffered saline (PBS), slices were blocked for $90 \mathrm{~min}$ in 10\% normal goat serum in PBS containing $0.2 \%$ Triton $\mathrm{X}-100$. The free-floating slices were incubated overnight at room temperature with rabbit-anti-PV (1:500, Swant, Marly, Switzerland) diluted in PBS containing 1\% normal goat serum and $0.2 \%$ Triton X-100. Additionally, this solution 
contained Cy-3-WFA (ca. $20 \mu \mathrm{g} / \mathrm{ml}$, prepared according to Brückner et al., 1996) to label PNNs. Thereafter, Alexa647-tagged donkey-anti-rabbit IgG, 1:500 in PBS containing 1\% normal goat serum and $0.2 \%$ Triton X-100 (Jackson ImmunoResearch, West Grove, PA, USA) was applied for $90 \mathrm{~min}$ at room temperature. After a final washing procedure, slices were mounted on gelatinized object slides, dried overnight at $4^{\circ} \mathrm{C}$ and coverslipped with Depex (Serva, Heidelberg, Germany). All steps were performed in the dark to avoid fading of the fluorescent dyes. Images were taken at a final magnification of $20 \times$ and $63 \times$ using a fluorescence microscope (Apotome, Zeiss, Jena, Germany).

\section{Statistics}

All data sets were first tested for normal distribution using the Kolmogorov-Smirnov test. Those showing normal distribution (induced spike-firing rates; MRP, input resistance, capacitance, time-constant and spike threshold, sEPSC frequency) are expressed as mean \pm SEM and were analyzed using analysis of variance (ANOVA) and post hoc Bonferroni test (or 2-sided $t$-test if only 2 groups were compared). sPSC amplitudes showing nonnormal distribution were analyzed with Kruskal-Wallis test if more than two groups were compared, otherwise Wilcoxon ranksum test had been applied. All statistical tests were performed using IBM SPSS statistical analysis package version 22.0 and considering a $p$-value less than 0.05 as a criterion to reject the null-hypothesis.

\section{RESULTS}

In total, 184 Cy3-WFA labeled cells were recorded in the whole-cell patch mode. Of these, 114 neurons were finally included in the analysis of induced spike-firing and a different set of 52 neurons was analyzed for spontaneous post-synaptic potentials (sPSPs), cells for which all test protocols could be successfully finished without signs of changes in the electrical stability (stable access resistance throughout recordings) and physiology of the cells. The majority of these cells showed the typical non-adapting firing characteristics of FSI, with firing frequencies increasing with current injection up to 300 spikes/s (see Supplementary Figure 1). The mean spike adaptation coefficient, calculated as the ratio of spike frequency close to the end of the current injection (750-950 ms) to spike frequency at onset of current injection (0-200 ms), was within the range reported earlier for FSI (e.g., Imbrosci et al., 2014). We deliberately did not narrow the range of adaptation coefficients and did not further exclude cells to avoid a selection bias that could hamper the rTMS effect. During whole-cell patch recordings cells were passively filled with Alexa488 for subsequent histochemical characterization using Cy3-WFA and anti-PV antibodies. However, due to weak staining in most cells only a few Alexa488-filled neurons could be visualized. All showed Cy3-WFA staining of surrounding PNNs and part of them displayed PV-labeling (for two examples, see Figure 2). A quantitative analysis regarding PV content became unrealistic due to the small number of stained cells and the possible dilution of the cytoplasm of FSI during patch-recordings.

\section{iTBS Effects on Induced Spike Firing}

We have previously shown (Mix et al., 2015) that the effect of iTBS, the lowering of PV expression in neurons ensheathed by Cy3-WFA-staining, is age-dependent, first evident at PD30-32 when the PNNs of FSI start to mature. Therefore, we investigated the iTBS effects on the electrical properties of FSI in animals spanning this critical age period (PD26-38) and additionally in somewhat older animals (PD40-42 and PD60-62). Since not enough cells could be successfully studied per PD in both groups (sham, verum iTBS), a grouping including data of three consecutive PD appeared appropriate to achieve reasonably balanced cell numbers per group (sham/verum): PD26-28, 6/9; PD29-31, 8/13; PD32-35, 6/8; PD36-38, 6/10; PD40-42, 11/18; PD60-62, 6/13.

FSI of sham and verum iTBS treated rats showed the typical increase in spike firing rate with increased current injections, approaching $150-250 \mathrm{~Hz}$ with $500 \mathrm{pA}$. However, cells of PD26-38 obtained from verum iTBS treated rats showed a higher induced spike firing rate than sham-treated animals with low injection currents (100-300 pA) while no difference was found for PD40-42 and PD60-62. The effect was strongest for FSI of PD32-35 (Figure 3). ANOVA calculation with the three factors AGE (6 groups), TMS (sham, verum) and CURRENT (100-500 pA) revealed a significant effect of all factors (AGE: $F_{(5)}=4.48, p=0.001$; TMS: $F_{(1)}=12.37, p<0.001$; CURRENT: $\left.F_{(4)}=52.798 ; p<0.001\right)$. Post hoc pairwise comparisons (Bonferroni) showed significant differences in induced spikefiring between all current injections except for the difference between 400 and $500 \mathrm{pA}$, indicating a saturation effect with strong stimulation. Significant interactions between factors AGE and TMS $\left(F_{(1,5)}=4.095 ; p=0.001\right)$ as well as between AGE and CURRENT $\left(F_{(5,4)}=1.736 ; p=0.025\right)$ indicate an age- and stimulation-dependent TMS effect. This was verified by a pairwise comparison of sham and verum treated groups, revealing significant differences for the following age groups and current injections: PD29-31 with $100 \mathrm{pA}$ (sham $81 \pm 10 \mathrm{~Hz}$ vs. verum $125 \pm 8 \mathrm{~Hz}, p=0.01)$, PD32-35 with 100,200 and $300 \mathrm{pA}$ ( 100 pA: sham $15 \pm 7 \mathrm{~Hz}$ vs. verum $127 \pm 31 \mathrm{~Hz}, p=0.02 ; 200 \mathrm{pA}$ : sham $49 \pm 10 \mathrm{~Hz}$ vs. verum $124 \pm 19 \mathrm{~Hz}, p=0.01 ; 300 \mathrm{pA}$ : sham $92 \pm 17 \mathrm{~Hz}$ vs. verum $155 \pm 12 \mathrm{~Hz}, p=0.01)$ and PD36-38 with $200 \mathrm{pA}$ current injection (sham $71 \pm 9 \mathrm{~Hz}$ vs. verum $108 \pm 16 \mathrm{~Hz}$, $p=0.03$ ). The regularity of induced spike sequences-quantified by the variance of inter-spike intervals-did not change as verified by pair-wise comparison of sham and verum groups as done for mean firing frequency ( $p>0.3$ for all pairs).

\section{iTBS Effects on Passive Cell Membrane Properties and Action Potential Threshold}

We further analyzed whether iTBS leads to changes of the passive membrane properties of FSIs or the threshold for eliciting action potentials in them. As visualized in Figure 4, only the MRP showed clear differences between verum and sham-treated animals in the age groups PD32 to PD38. ANOVA resulted in a significant interaction of factors AGE and TMS $\left(F_{(1,5)}=3.017\right.$, $p=0.013)$ and post hoc comparison of factor TMS revealed significant differences in MRP for PD32-35 (sham $-71 \pm 2 \mathrm{mV}$ 

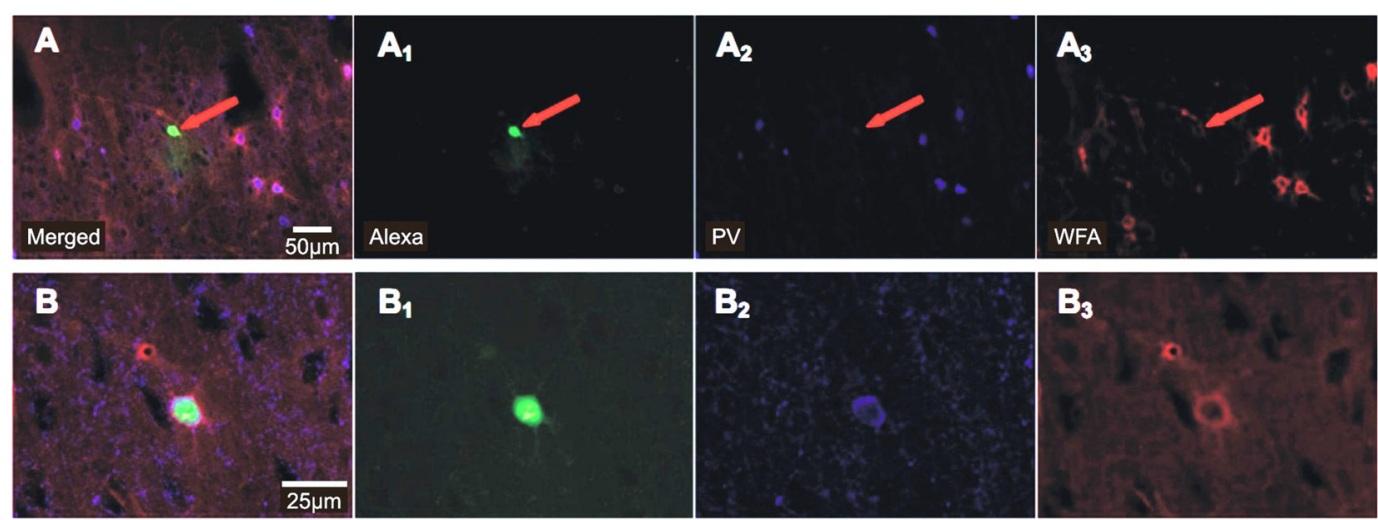

$B_{1}$

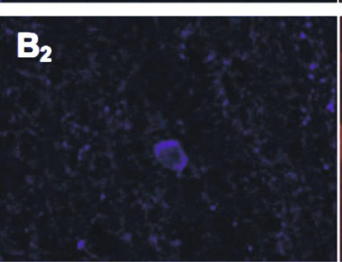

$\mathrm{B}_{3}$
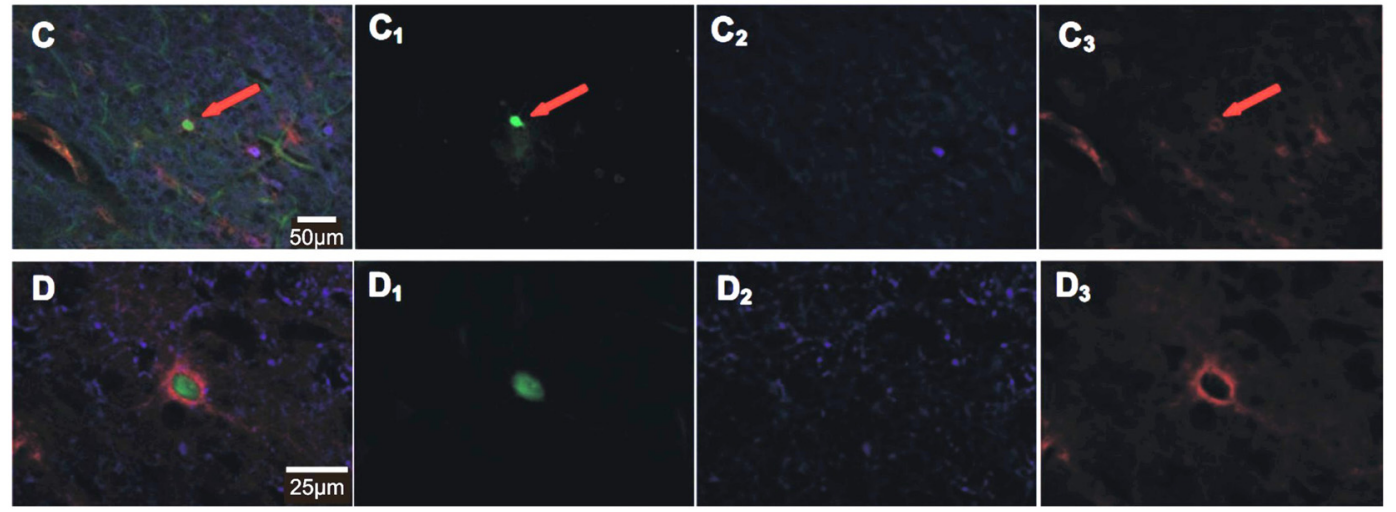

FIGURE 2 | Histochemical staining of recorded FSIs for Alexa488, parvalbumin (PV) and Cy3-WFA. Photomicrographs of 30 mm-thick sections obtained from the $290 \mu \mathrm{m}$ thick brain slices after recordings show Alexa488 stain (green), parvalbumin (PV, Alexa647, blue) and WFA (perineuronal nets, Cy3, red) of two different FSIs (A-D) at different magnification (20x in $\mathbf{( A )}$ and $\mathbf{( C )}, 63 \times$ in $\mathbf{( B )}$ and $(\mathbf{D})$ ). Merged images to the left $(\mathbf{A}-\mathbf{D})$, individual stains to the right $\left(\mathbf{A}_{\mathbf{1}}-\mathbf{D}_{\mathbf{3}}\right)$. The red arrows indicate labeling in the images of lower magnification. Notice, that the cell indicated by an arrow in (A) was PV-immunoreactive whereas the marked cell in (C) was PV-immunonegative.

vs. verum $-57 \pm 3 \mathrm{mV}, p=0.009$ ) and PD36-38 (sham $-72 \pm 3 \mathrm{mV}$ vs. verum $-62 \pm 2 \mathrm{mV}, p=0.03)$. No other comparisons revealed significant group differences. The more depolarized MRP of cells of the verum group appears to be primarily related to a more hyperpolarized level in the shamtreated rats at this age compared to younger and older animals. Cross-reference to induced spike-firing (Figure 3) reveals that also firing rate induced by weak currents is lower around this age (PD32-28) compared to younger and older animals of the sham group (100 pA, $p<0.05$ ). Other cell membrane properties like input resistance, time constant, capacitance and action potential threshold appeared not to be affected by iTBS. Only the input resistance showed a marginally significant difference for the PD29-31 groups (sham $111 \pm 12 \mathrm{M} \Omega$ vs. verum $148 \pm 10 \mathrm{M} \Omega$, $p=0.04)$.

\section{iTBS Effects on sPSCs}

The analysis of spontaneous synaptic currents was performed on a different set of animals and Cy3-WFA-labeled cells to prevent changes in the physiological conditions of the small FSI due to long recording times. Only rats aged 29-42 days were included, divided into three groups to address the range of age with the strongest iTBS effects on induced spike-firing and MRP at the transition of the former groups PD32-35 and PD36-38 (PD34-36; sham: $N=10$, verum: $N=8$ ), as well as the flanking younger (PD29-31; sham: $N=11$ cells, verum: $N=8$ ) and older former groups (PD40-42; sham: $N=8$, verum: $N=7$ ). After cells had been verified as fast-spiking, using a $300 \mathrm{pA}$ injection current (as described above), sPSCs were recorded at a holding potential of $-80 \mathrm{mV}$, first without, then with the $\mathrm{GABA}_{\mathrm{A}}$ receptor blocker PTX added to the bath solution (Figure 5A). Since the pipette was filled with a solution containing $34.5 \mathrm{mM}$ chloride, the calculated reversal potential for chloride currents was about $-35 \mathrm{mV}$, thus guaranteeing sufficient potential difference to drive sIPSCs at a holding potential of $-80 \mathrm{mV}$. Therefore, the first set of measurements without PTX included sEPSCs and sIPSCs of same current polarity, while the second measurements with PTX added to the bath solution should be free of sIPSCs. A group comparison using ANOVA with factors AGE, TMS and PTX revealed a significant effect only for factor TMS $\left(F_{(1)}=21.854\right.$; $p<0.001)$. Post hoc comparison of the TMS groups yielded significantly enhanced sPSCs rate (sEPSCs + sIPSCs) with iTBS only in animals aged between PD29 and PD36 (PD29-31: sham $4.75 \pm 1.1 \mathrm{~Hz}$ vs. verum $10.51 \pm 1.95 \mathrm{~Hz}, p=0.014$; PD34-36: sham $3.51 \pm 0.58 \mathrm{~Hz}$ vs. verum $7.65 \pm 2.1 \mathrm{~Hz}, p=0.054$; 


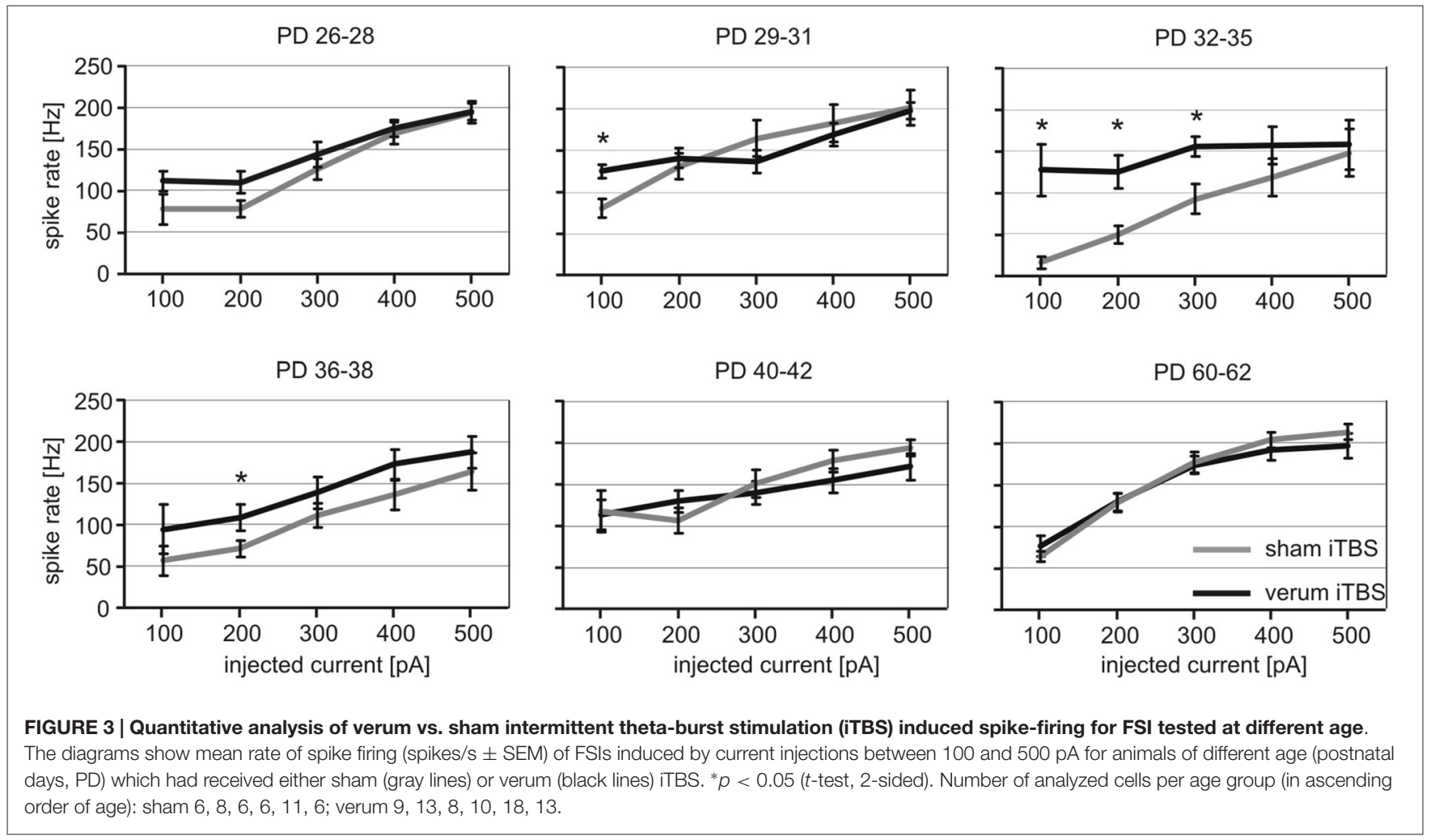

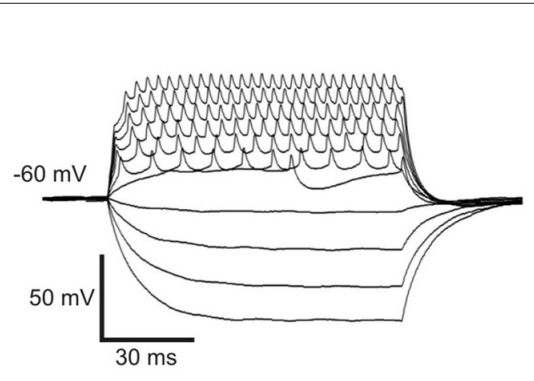

Membrane resting potential

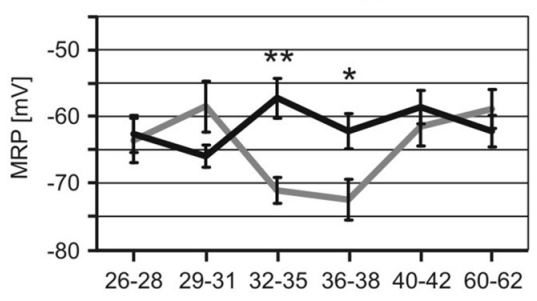

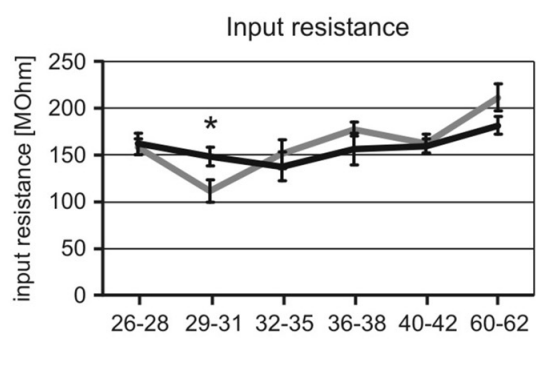

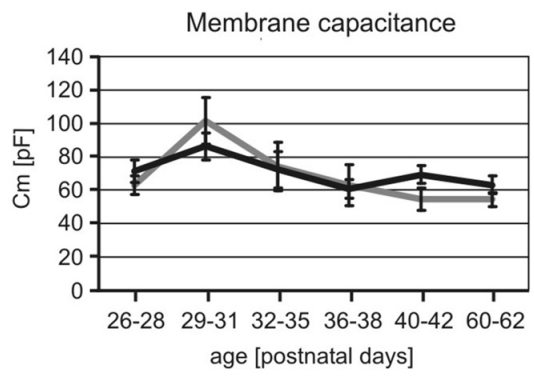

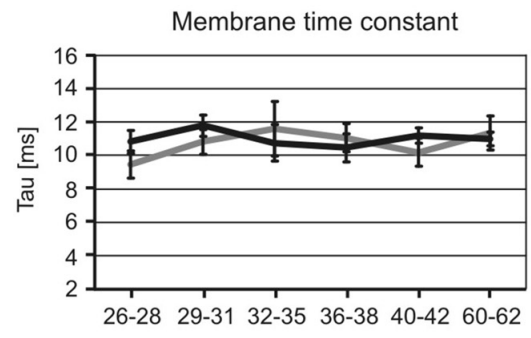

Action potential threshold

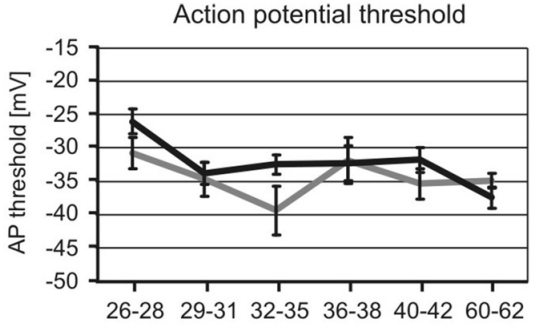

FIGURE 4 | Changes in cell membrane characteristics of sham and verum iTBS-treated rats of different age. Example voltage traces obtained with -50 to $+115 \mathrm{pA}$ current injections to determine membrane resting potential (MRP) and input resistance are shown to the upper left. Other membrane parameters were determined in voltage clamp mode, testing $-100 \mathrm{mV}$ to $-10 \mathrm{mV}$ at steps of $10 \mathrm{mV}$. Diagrams show mean values ( $\pm \mathrm{SEM}$ ) of MRP, input resistance, time constant, capacitance and action potential threshold plotted vs. age for sham (gray) and verum (black) iTBS-treated animals. ${ }^{*} p<0.05,{ }^{* *} p<0.01(t$-test, 2 -sided). Number of analyzed cells per age group (in ascending order of age): sham 8, 8, 6, 7, 12, 6; verum 11, 15, 9, 10, $25,15$.

see Figures 5B-D). Adding PTX to the bath solution had little effect on sPSC frequency in general, indicating that the synaptic currents measured at $-80 \mathrm{mV}$ were mostly mediated by excitatory inputs. Significance levels for differences between verum and sham-treated animals persisted (PD29-31: sham $2.9 \pm 0.75 \mathrm{~Hz}$ vs. verum $9.25 \pm 2.58 \mathrm{~Hz}, p=0.015)$ or 
A

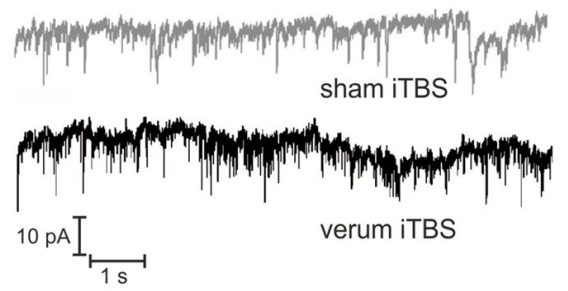

B

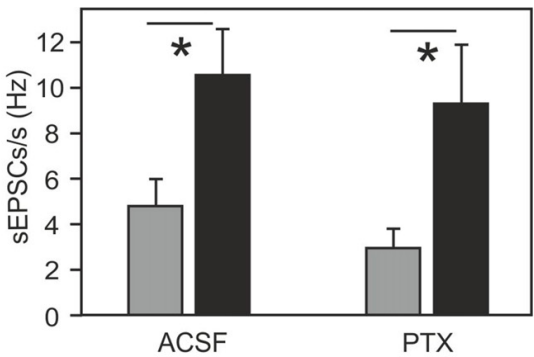

C

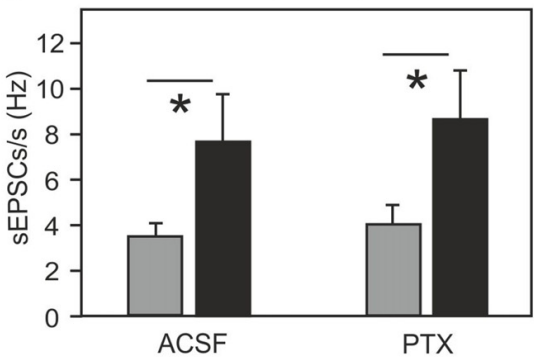

D

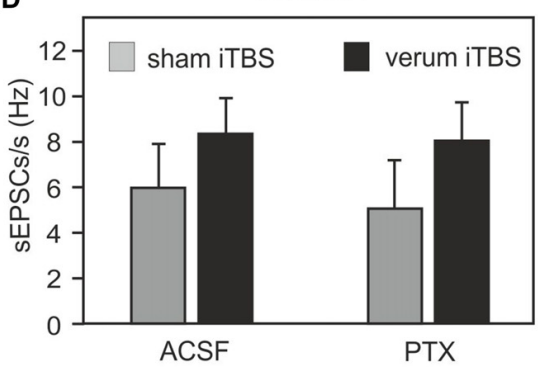

E

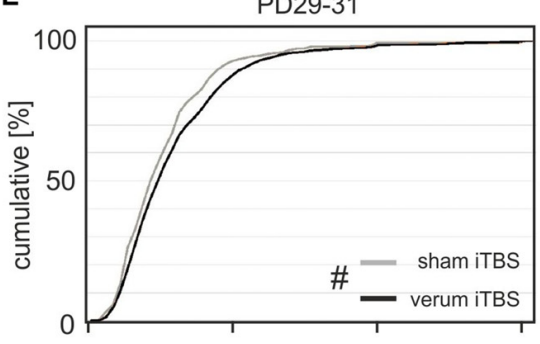

F

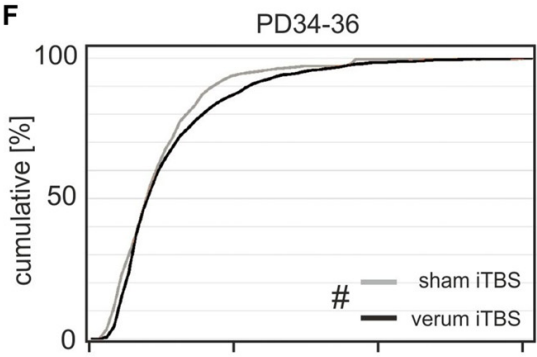

G
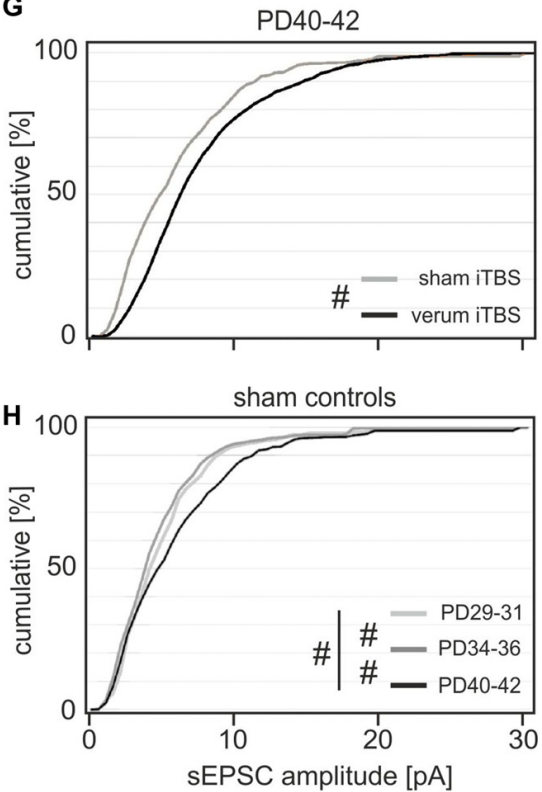

FIGURE 5 | Frequency and amplitudes of spontaneous postsynaptic currents (sPSCs) in FSIs of sham or verum iTBS-treated rats of different age. (A) Example traces showing sPSC recordings in FSls of sham (gray) and verum (black) iTBS-treated rats at PD35. (B-D) Bar diagrams show mean frequency of sPSCs ( \pm SEM) for sham (gray) or verum (black) iTBS-treated rats of three different age ranges. Total sPSCs including excitatory (sEPSCs) and inhibitory (sIPSCs) currents were recorded with the GABA , receptor blocker picrotoxin (PTX) not added to the bath solution (ACSF, left columns). sEPSCs were selected by blocking sIPSCs with PTX (right columns) which resulted in little reduction in SPSC rate. (E-G) Cumulative plots of SEPSC amplitudes for animals of different age having received either sham (gray) or verum (black) iTBS. Verum iTBS causes a shift towards larger sEPSCs primarily in the older animals (PD40-42). (H) Cumulative plot of sEPSC amplitudes for the sham-control animals of different age. sEPSC amplitudes increased between PD34-36 and PD40-42. * $p<0.05$ ( $t$-test, 2-sided), $\# p<0.001$ (Wilcoxon rank-sum test).

slightly improved (PD34-36: sham $4.07 \pm 0.85 \mathrm{~Hz}$ vs. verum $8.67 \pm 2.1 \mathrm{~Hz}, p=0.04)$.

\section{iTBS Effects on sEPSC Amplitude}

In addition to frequency, we analyzed the amplitude distribution of sEPSCs in FSI of sham and verum iTBS treated animals (PTX added to bath solution). Comparison of sham and verum treated groups using Wilcoxon rank-sum test indicates significantly increased sEPSC amplitudes in all age groups $(p<0.001)$ with a stronger increase evident for the oldest group (PD40-42, see cumulative amplitude plots of Figures 5E-G). Measured at $50 \%$ of cumulative amplitudes, sEPSCs amplitudes were on average $0.5 \mathrm{pA}, 0.5 \mathrm{pA}$ and $2 \mathrm{pA}$ larger for the verum groups PD29-31, PD34-36 and PD40-42, respectively, compared to 
corresponding sham groups. At $75 \%$ cumulated amplitudes the differences increased to $1.5 \mathrm{pA}, 1.5 \mathrm{pA}$ and $2.5 \mathrm{pA}$, respectively. A separate comparison of the sEPSC amplitudes of the sham-groups also revealed a significant increase with age ( $p=0.047$, Kruskal-Wallis test for comparison of all groups; $p<0.001$ for pair-wise comparison of age-groups with Wilcoxon rank-sum test, Figure $\mathbf{5 H}$ ). Measured at $50 \%$ of cumulative amplitudes, sEPSCs somewhat decreased between PD29-31 and PD34-36 (-1.5 pA) but increased between PD34-36 and PD40-42 (+2.5 pA). Corresponding differences at $75 \%$ cumulated amplitudes are $-0.5 \mathrm{pA}$ and $+2 \mathrm{pA}$, respectively.

\section{DISCUSSION}

\section{Summary of Findings}

Our current ex vivo-in vitro studies demonstrate that iTBS applied via TMS to the rat brain alters the electrical properties of cortical FSI compared to age-matched sham-stimulated controls. We further show that the iTBS effect varies in an age-dependent fashion during early cortical development and that the strongest effects were evident during the phase of cortical critical period when FSIs mature in an activity-dependent fashion (see Hensch, 2005). The major iTBS effects seen in the acute brain slice preparations were: (1) an enhanced excitability of FSIs between PD 29 and 36 (PD29-36), evident as an increased action potential firing frequency in response to small depolarizing current injections, accompanied by a less hyperpolarized membrane potential; and (2) an enhanced activity level of the cortical network, evident by increased frequency of sEPSCs in FSIs. An iTBS-induced increase in sEPSC amplitude was stronger for animals older than 33 days when sEPSC amplitudes generally increased with age. Passive cell membrane properties like membrane input resistance, capacitance, time constant and the action potential threshold did not change after iTBS.

\section{Possible Cellular Mechanisms}

Although we cannot demonstrate discrete cellular mechanisms of these changes in FSI and network excitability, our results demonstrate that the iTBS protocol applied via TMS to the rat neocortex is able to affect the electrical properties of FSIs in addition to the biochemical changes demonstrated previously. Our in vivo TMS studies revealed that iTBS applied with a total of 1800 pulses ( 3 blocks at 600 pulses at 15 min intervals) strongly reduced the cortical expression of PV in adult (Benali et al., 2011; Hoppenrath and Funke, 2013; Volz et al., 2013; Mix et al., 2014) but also in younger, but more than 32-dayold rats (Mix et al., 2015). Usually, PV was strongly reduced in $40-50 \%$ of the cells compared to control or sham-stimulated animals. Those cells with reduced PV expression still appeared vital as demonstrated by the normal pattern of the PNNs, the unchanged expression of Kv3.1b-type potassium channels and the integrity of synaptic connections (Benali et al., 2011). Also the electrophysiological data obtained in the current study indicate no pathological state of FSIs in iTBS-treated animals. Almost all Cy3-WFA pre-labeled neurons showed the typical non-adapting fast-spiking behavior to constant depolarizing current injections, with spike train frequencies between 30 and $200 \mathrm{~Hz}$ (Cauli et al., 1997; Uematsu et al., 2008; Orduz et al., 2013). Also an adaptation coefficient scattering somewhat around 0.88 is typical for FSI (see Imbrosci et al., 2014). Spike width appeared small $(<0.5 \mathrm{~ms}$; at half height) but could not be reliably measured with the sampling frequency related to the current injection protocol $(2.73 \mathrm{kHz})$. However, FSIs recorded from iTBS-treated rats showed on average a higher excitability to weak depolarizing current injections. It is likely that the enhanced excitability is a result of the reduced PV expression. Orduz et al. (2013) recently demonstrated a very similar relationship between PV expression and induced spike sequences in FSIs of young (PD18-24) PV-knockout mice $\left(\mathrm{PV}^{-/}\right)$. Compared to wild-type controls, $\mathrm{PV}^{-/-}$mice exhibited a $100-200 \%$ increase in spike-firing frequency particularly at low current injections (100-200 pA) while no mean difference was found with strong current injection (380 pA). This difference disappeared if EGTA, a calcium chelator exhibiting similar calcium-buffer kinetics as $\mathrm{PV}$, was added to the patch-pipette solution during recordings of FSIs with $\mathrm{PV}^{-/-}$phenotype. The authors of this study further demonstrated that a faster deactivation of SK-type calciumdependent potassium channels is fundamental to the increased firing frequency of FSIs of the $\mathrm{PV}^{-/-}$phenotype (see also Gall et al., 2003; Bischop et al., 2012) and related to the changed calcium-buffering capacity of the cells missing PV. Although the studies of Orduz et al. (2013) were done on striatal neurons of mice aged PD29 onwards and therefore, cannot be transferred to neocortical FSIs in a one-to-one fashion, their findings are strong indications that the calcium-buffering capacity of PV regulates the excitability and activity rate of FSIs. Unfortunately, we were unable to confirm that the cells recorded in slices from iTBS-treated rats actually had reduced PV expression, because subsequent quantification of cytosolic PV concentration appeared to be unrealistic. Nevertheless, due to our previous immunohistochemical studies on rats of matching age and strain (Mix et al., 2015) the likelihood of recording a neuron with reduced PV expression (but normal PNNs) is $40-50 \%$ in iTBS-treated rats compared to almost $0 \%$ in sham-treated animals, meaning that the differences between verum and sham-stimulated animals may be even stronger if we would have recorded only neurons certainly missing the PV expression.

\section{Cortical Network Activity}

Within the same range of age, iTBS caused an increase in sEPSCs in FSIs indicating an increased cortical network activity. This finding is in agreement with the idea of increased cortical excitability after iTBS according to human (Huang et al., 2005; Di Lazzaro et al., 2010) but also animal studies (Benali et al., 2011; Thimm and Funke, 2015). Although spontaneous excitatory input at a rate of about $5 \mathrm{~Hz}$ appears to be insufficient to result in a steady $10 \mathrm{mV}$ depolarization of the membrane potential of FSIs compared to the $2-3 \mathrm{~Hz}$ input in the control condition, we cannot exclude that increased EPSC frequency following iTBS contributes to the cell's increased excitability. A study of Chance et al. (2002) demonstrated that high-frequency synaptic noise (but balanced for excitation [7000 Hz] and inhibition $[3000 \mathrm{~Hz}]$ ) 
can modulate the cells response gain to driving inputs. However, the effects on response gain considerably differed from those we observed: instead of increased steepness of the stimulus-response curve we found increased responses to weak stimuli. A more detailed quantification of the contribution of $\mathrm{Ca}^{2+}$-buffering by PV and synaptic input to the cell's excitability could be achieved by blocking the latter. However, our first measurements aimed at showing the iTBS effect on FSIs for a condition close to the physiological state. The effect of increased spontaneous activity after iTBS was weaker but not completely absent in the older animals. Also previous studies applying iTBS to anesthetized adult rats (2-3 month) revealed an increase in cortical excitability expressed as increased spontaneous and sensory stimulation driven neuronal activity (Benali et al., 2011; Thimm and Funke, 2015; see also Supplementary Figure 2). On the other hand, sEPSC amplitudes in the ex vivo-in vitro recordings of FSIs increased not only after iTBS primarily in the elder animals (PD 40-42) but progressively increased also with age, likely a sign of maturing excitatory synapses on FSIs.

\section{Age and Developmental Cortical State}

The rTMS studies in adult rats indicate a disinhibitory effect of iTBS since sensory responses of the somatosensory cortex increased (Benali et al., 2011; Thimm and Funke, 2015). In addition, rats showed a better tactile learning performance after iTBS which was correlated with decreased PV expression after iTBS and re-instatement of PV expression after learning (Mix et al., 2010). These findings are in line with improved human tactile and motor performance when cortical GABA content is altered (Dinse et al., 2003; Kim et al., 2014; Heba et al., 2016) and fit the hypothesis of disinhibition-guided learning (Letzkus et al., 2015). In our current study, we found no indications of reduced activity in FSIs after iTBS but an increased excitability to weak depolarizing stimuli. It is very likely that the physiological state of the FSIs during the cortical critical period very much differs from the adult state when exhibiting an activity-driven episode of maturation that goes along with synaptic pruning, potentiation of surviving synapses and restriction of neuronal plasticity (Hensch, 2005; Sale et al., 2010) with growth of the PNNs (Köppe et al., 1997) frequently surrounding $\mathrm{PV}^{+}$neurons (Härtig et al., 1992, 1999; Wegner et al., 2003). In particular, inhibition mediated via the $\mathrm{PV}^{+}$FSIs appears to be a key mechanism in this process (Huang et al., 1999; Chattopadhyaya et al., 2004) since it reduces the ratio of uncorrelated spontaneous input to well correlated synaptic activity driven by sensory inputs (Maffei et al., 2004, 2006; Toyoizumi et al., 2013; Chen et al., 2014). $\mathrm{PV}^{+}$interneurons apparently exhibit a higher degree of responsiveness and plasticity to driving inputs at this stage, resulting in a stronger change in excitability between PD 29-38 also when cortical inputs are artificially activated via highfrequency rTMS. At the same age iTBS was found to reduce the expression of PV which did not occur in younger animals (Mix et al., 2015). Since the way we applied rTMS favors the activation of callosal axons rather than short-projecting cells within the gray matter (low intensity mediolateral oriented electric field), FSIs can be excited only trans-synaptically via collaterals of the callosal axons (see Benali et al., 2011; Funke and Benali, 2011). As long as these synapses are still immature, no effect can be expected. Later, but still during the early phase of critical period, these synapses will be strengthened in an activity-dependent manner while inhibition is still weak (Kuhlman et al., 2013). A lack of sensory activity as during dark-rearing of the animals impairs this maturation process (Fagiolini et al., 1994; Pizzorusso et al., 2000). We could recently show that iTBS applied during this critical period in darkreared rats is able to substitute for the missing visual input, restoring the animal's visual performance (Castillo-Padilla and Funke, 2016). This was accompanied by increased cortical levels of BDNF, a possible mediator of improved functional maturation of FSI (Gianfranceschi et al., 2003; Jiao et al., 2011).

\section{Translational Aspects}

Non-invasive brain stimulation appears to be a promising tool for treating neurological and psychiatric disorders (Lefaucheur et al., 2014). Of particular interest in this respect is the chance to modulate neuronal plasticity processes, e.g., by re-instating a juvenile-like state of cortical plasticity as during cortical critical period. Attempts have been made to modify cortical inhibition by varying the sensory environment (Baroncelli et al., 2010a,b, 2011), by pharmacological means (Gianfranceschi et al., 2003; Maya Vetencourt et al., 2008; Baroncelli et al., 2010b; Harauzov et al., 2010) and even by transplanting precursor cells of inhibitory interneurons to the adult cortex (Southwell et al., 2010; Davis et al., 2015) to achieve such a state. Also cortical injury appears to trigger such processes (Imbrosci et al., 2014; Nahmani and Turrigiano, 2014). The findings of our current and recent studies (Castillo-Padilla and Funke, 2016; Mix et al., 2015) with iTBS applied during cortical critical period indicate that non-invasive brain stimulation could affect early cortical developmental plasticity by modulating the activity of FSIs. This would be of potential benefit if activity-dependent maturation of FSIs is impaired due to sensory deprivation or disturbed glutamatergic input as discussed for developmental causes of neuropsychiatric diseases (Taylor and Tso, 2015). However, adequate work in children is missing and those in animal models are rare so far, demanding further studies on this important aspect. A couple of studies-including the use of TMS-indicate that cortical excitability and plasticity change with age accompanied by changes in the impact of inhibitory systems (Rogasch et al., 2009; Todd et al., 2010; Bashir et al., 2014). A recent study using iTBS, however, showed no clear age-dependent variations but a high variability of TMS effects in general (Dickins et al., 2015). Besides general processes of cellular aging, experience-dependent changes in network wiring strategies are discussed as contributing factors (e.g., Bernard and Seidler, 2012). Therefore, cortical networks of children are apparently differently responsible to natural and artificial cortical stimulation and also the effects of rTMS may differ. So far, little is known about iTBS effects in children but it appears to be safe since adverse effects are rare and do not outnumber those of seen in adults (Hong et al., 2015; Pedapati et al., 2015).

A further challenge is the analysis of the state-dependence of brain stimulation and the comparison of different stimulation 
protocols. The two established rTMS theta-burst protocols iTBS and cTBS have initially been shown to induce opposite changes in cortical excitability (Huang et al., 2005; Di Lazzaro et al., 2010), recent studies however demonstrate a strong inter-individual variation which obviously relates to varying states of cortical network connectivity (Hamada et al., 2013; Nettekoven et al., 2015) and homeostatic plasticity (Karabanov et al., 2015). Although we found partly opposite effects of iTBS and cTBS in our rat studies on neuronal activity marker expression (Trippe et al., 2009; Benali et al., 2011) and learning performance (Mix et al., 2010), we also found a clear strain-dependent variation especially of the cTBS effect (Mix et al., 2014). The effects of cTBS appear to change also if applied with different numbers of pulses (Gentner et al., 2008; Gamboa et al., 2010) and if applied repeatedly (Gamboa et al., 2011; Thimm and Funke, 2015). Therefore, we focused our studies on the less variable iTBS effect. Nevertheless, further studies on the age-dependence of cTBS effect are required to better understand the reasons for the variable stimulation effects.

\section{AUTHOR CONTRIBUTIONS}

$\mathrm{KH}$ conducted the experiments, analyzed the data and wrote a first version of the manuscript as part of her $\mathrm{PhD}$ thesis. The experiments were carried out in the Department of Neurophysiology, Ruhr-University Bochum. KF and WH designed the study and revised the manuscript. KF proofed the

\section{REFERENCES}

Baroncelli, L., Braschi, C., Spolidoro, M., Begenisic, T., Sale, A., and Maffei, L. (2010a). Nurturing brain plasticity: impact of environmental enrichment. Cell Death Differ. 17, 1092-1103. doi: 10.1038/cdd.2009.193

Baroncelli, L., Maffei, L., and Sale, A. (2011). New perspectives in amblyopia therapy on adults: a critical role for the excitatory/inhibitory balance. Front. Cell. Neurosci. 5:25. doi: 10.3389/fncel.2011.00025

Baroncelli, L., Sale, A., Viegi, A., Maya Vetencourt, J. F., De Pasquale, R., Baldini, S., et al. (2010b). Experience-dependent reactivation of ocular dominance plasticity in the adult visual cortex. Exp. Neurol. 226, 100-109. doi: 10.1016/j.expneurol.2010.08.009

Bashir, S., Perez, J. M., Horvath, J. C., Pena-Gomez, C., Vernet, M., Capia, A., et al. (2014). Differential effects of motor cortical excitability and plasticity in young and old individuals: a transcranial magnetic stimulation (TMS) study. Front. Aging Neurosci. 6:111. doi: 10.3389/fnagi.2014. 00111

Beasley, C. L., and Reynolds, G. P. (1997). Parvalbumin-immunoreactive neurons are reduced in the prefrontal cortex of schizophrenics. Schizophr. Res. 24, 349-355. doi: 10.1016/s0920-9964(96)00122-3

Beasley, C. L., Zhang, Z. J., Patten, I., and Reynolds, G. P. (2002). Selective deficits in prefrontal cortical GABAergic neurons in schizophrenia defined by the presence of calcium-binding proteins. Biol. Psychiatry 52, 708-715. doi: 10 . 1016/s0006-3223(02)01360-4

Benali, A., Trippe, J., Weiler, E., Mix, A., Petrasch-Parwez, E., Girzalsky, W., et al. (2011). Theta-burst transcranial magnetic stimulation alters cortical inhibition. J. Neurosci. 30, 1193-1203. doi: 10.1523/JNEUROSCI.137910.2011

Bernard, J. A., and Seidler, R. D. (2012). Hand dominance and age have interactive effects on motor cortical representations. PLoS One 7:e45443. doi: 10.1371/journal.pone.0045443 data analysis and statistics, and helped with the design of the figures. WH prepared the Cy3-WFA for staining of perineuronal nets in the living slice. All authors approved the final submission and agree to be accountable for all aspects of the work in ensuring that questions related to the accuracy or integrity of any part of the work are appropriately investigated and resolved.

\section{FUNDING}

This study has been supported by grants from the Deutsche Forschungsgemeinschaft (DFG) to KF (SFB 874, TP A4 and FU256/3-2) and is also a matter of the competence network on neuropsychiatric diseases of the German Federal Ministry of Education and Research (BMBF, with funding to KF for project: 01EE1403B).

\section{ACKNOWLEDGMENTS}

The authors are grateful to Ute Neubacher and Dimitrula Winkler for support of histochemical work.

\section{SUPPLEMENTARY MATERIAL}

The Supplementary Material for this article can be found online at: http://journal.frontiersin.org/article/10.3389/fncir.2016.000 22/abstract

Bischop, D. P., Orduz, D., Lambot, L., Schiffmann, S. N., and Gall, D. (2012). Control of neuronal excitability by calcium binding proteins: a new mathematical model for striatal fast-spiking interneurons. Front. Mol. Neurosci. 5:78. doi: 10.3389/fnmol.2012.00078

Brückner, G., Brauer, K., Härtig, W., Wolff, J. R., Rickmann, M. J., Derouiche, A., et al. (1993). Perineuronal nets provide a polyanionic, glia-associated form of microenvironment around certain neurons in many parts of the rat brain. Glia 8, 183-200. doi: 10.1002/glia.440080306

Brückner, G., Bringmann, A., Köppe, G., Härtig, W., and Brauer, K. (1996). In vivo and in vitro labelling of perineuronal nets in rat brain. Brain Res. 720, 84-92. doi: 10.1016/0006-8993(96)00152-7

Castillo-Padilla, D. V., and Funke, K. (2016). Effects of chronic iTBS-rTMS and enriched environment on visual cortex early critical period and visual pattern discrimination in dark-reared rats. Dev. Neurobiol. 76, 19-33. doi: 10. 1002/dneu.22296

Cauli, B., Audinat, E., Lambolez, B., Angulo, M. C., Ropert, N., Tsuzuki, K., et al. (1997). Molecular and physiological diversity of cortical nonpyramidal cells. J. Neurosci. 17, 3894-3906.

Chance, F. S., Abbott, L. F., and Reyes, A. D. (2002). Gain modulation from background synaptic input. Neuron 35, 773-782. doi: 10.1016/s08966273(02)00820-6

Chattopadhyaya, B., DiCristo, G., Higashiyama, H., Knott, G. W., Kuhlman, S. J., Welker, E., et al. (2004). Experience and activity-dependent maturation of perisomatic GABAergic innervation in primary visual cortex during a postnatal critical period. J. Neurosci. 24, 9598-9611. doi: 10.1523/jneurosci.1851-04.2004

Chen, X. J., Rasch, M. J., Chen, G., Ye, C. Q., Wu, S., and Zhang, X. H. (2014). Binocular input coincidence mediates critical period plasticity in the mouse primary visual cortex. J. Neurosci. 34, 2940-2955. doi: 10.1523/JNEUROSCI. 2640-13.2014

Davis, M. F., Figueroa Velez, D. X., Guevarra, R. P., Yang, M. C., Habeeb, M., Carathedathu, M. C., et al. (2015). Inhibitory neuron transplantation into adult 
visual cortex creates a new critical period that rescues impaired vision. Neuron 86, 1055-1066. doi: 10.1016/j.neuron.2015.03.062

Dickins, D. S., Sale, M. V., and Kamke, M. R. (2015). Plasticity induced by intermittent theta burst stimulation in bilateral motor cortices is not altered in older adults. Neural Plast. 2015:323409. doi: 10.1155/2015/ 323409

Di Lazzaro, V., Pilato, F., Dileone, M., Profice, P., Capone, F., Ranieri, F., et al. (2008a). Modulating cortical excitability in acute stroke: a repetitive TMS study. Clin. Neurophysiol. 119, 715-723. doi: 10.1016/j.clinph.2007. 11.049

Di Lazzaro, V., Pilato, F., Dileone, M., Profice, P., Oliviero, A., Mazzone, P., et al. (2008b). The physiological basis of the effects of intermittent theta burst stimulation of the human motor cortex. J. Physiol. 586, 3871-3879. doi: 10. 1113/jphysiol.2008.152736

Di Lazzaro, V., Profice, P., Pilato, F., Dileone, M., Oliviero, A., and Ziemann, U. (2010). The effects of motor cortex rTMS on corticospinal descending activity. Clin. Neurophysiol. 121, 464-473. doi: 10.1016/j.clinph.2009. 11.007

Dinse, H. R., Ragert, P., Pleger, B., Schwenkreis, P., and Tegenthoff, M. (2003). Pharmacological modulation of perceptual learning and associated cortical reorganization. Science 301, 91-94. doi: 10.1126/science.1085423

Fagiolini, M., Pizzorusso, T., Berardi, N., Domenici, L., and Maffei, L. (1994). Functional postnatal development of the rat primary visual cortex and the role of visual experience: dark rearing and monocular deprivation. Vision Res. 34, 709-720. doi: 10.1016/0042-6989(94)90210-0

Fitzgerald, P. B. (2011). The emerging use of brain stimulation treatments for psychiatric disorders. Aust. N. Z. J. Psychiatry 45, 923-938. doi: 10. 3109/00048674.2011.615294

Funke, K., and Benali, A. (2011). Modulation of cortical inhibition by rTMS-findings obtained from animal models. J. Physiol. 589, 4423-4435. doi: 10.1113/jphysiol.2011.206573

Gall, D., Roussel, C., Susa, I., D’Angelo, E., Rossi, P., Bearzatto, B., et al. (2003). Altered neuronal excitability in cerebellar granule cells of mice lacking calretinin. J. Neurosci. 23, 9320-9327.

Gamboa, O. L., Antal, A., Laczo, B., Moliadze, V., Nitsche, M. A., and Paulus, W. (2011). Impact of repetitive theta burst stimulation on motor cortex excitability. Brain Stimul. 4, 145-151. doi: 10.1016/j.brs.2010.09.008

Gamboa, O. L., Antal, A., Moliadze, V., and Paulus, W. (2010). Simply longer is not better: reversal of theta burst after-effect with prolonged stimulation. Exp. Brain Res. 204, 181-187. doi: 10.1007/s00221-0102293-4

Gentner, R., Wankerl, K., Reinsberger, C., Zeller, D., and Classen, J. (2008). Depression of human corticospinal excitability induced by magnetic thetaburst stimulation: evidence of rapid polarity-reversing metaplasticity. Cereb. Cortex 18, 2046-2053. doi: 10.1093/cercor/bhm239

Gianfranceschi, L., Siciliano, R., Walls, J., Morales, B., Kirkwood, A., Huang, Z. J., et al. (2003). Visual cortex is rescued from the effects of dark rearing by overexpression of BDNF. Proc. Natl. Acad. Sci. U S A 100, 12486-12491. doi: 10. 1073/pnas.1934836100

Grefkes, C., Nowak, D. A., Wang, L. E., Dafotakis, M., Eickhoff, S. B., and Fink, G. R. (2010). Modulating cortical connectivity in stroke patients by rTMS assessed with fMRI and dynamic causal modeling. Neuroimage 50, 233-242. doi: 10.1016/j.neuroimage.2009.12.029

Hamada, M., Murase, N., Hasan, A., Balaratnam, M., and Rothwell, J. C. (2013). The role of interneuron networks in driving human motor cortical plasticity. Cereb. Cortex 23, 1593-1605. doi: 10.1093/cercor/bhs147

Harauzov, A., Spolidoro, M., DiCristo, G., De Pasquale, R., Cancedda, L., Pizzorusso, T., et al. (2010). Reducing intracortical inhibition in the adult visual cortex promotes ocular dominance plasticity. J. Neurosci. 30, 361-371. doi: 10. 1523/JNEUROSCI.2233-09.2010

Härtig, W., Brauer, K., and Brückner, G. (1992). Wisteria floribunda agglutininlabelled nets surround parvalbumin-containing neurons. Neuroreport 3, 869-872. doi: 10.1097/00001756-199210000-00012

Härtig, W., Derouiche, A., Welt, K., Brauer, K., Grosche, J., Mäder, M., et al. (1999). Cortical neurons immunoreactive for the potassium channel Kv3.1b subunit are predominantly surrounded by perineuronal nets presumed as a buffering system for cations. Brain Res. 842, 15-29. doi: 10.1016/s00068993(99)01784-9
Hashimoto, T., Volk, D. W., Eggan, S. M., Mirnics, K., Pierri, J. N., Sun, Z., et al. (2003). Gene expression deficits in a subclass of GABA neurons in the prefrontal cortex of subjects with schizophrenia. J. Neurosci. 23, 6315-6326.

Heba, S., Puts, N. A., Kalisch, T., Glaubitz, B., Haag, L. M., Lenz, M., et al. (2016). Local GABA concentration predicts perceptual improvements after repetitive sensory stimulation in humans. Cereb. Cortex 26, 1295-1301. doi: 10. 1093/cercor/bhv296

Hensch, T. K. (2005). Critical period plasticity in local cortical circuits. Nat. Rev. Neurosci. 6, 877-888. doi: 10.1038/nrn1787

Hong, Y. H., Wu, S. W., Pedapati, E. V., Horn, P. S., Huddleston, D. A., Laue, C. S., et al. (2015). Safety and tolerability of theta burst stimulation vs. single and paired pulse transcranial magnetic stimulation: a comparative study of 165 pediatric subjects. Front. Hum. Neurosci. 9:29. doi: 10.3389/fnhum.2015. 00029

Hoppenrath, K., and Funke, K. (2013). Time-course of changes in neuronal activity markers following iTBS-TMS of the rat neocortex. Neurosci. Lett. 536, 19-23. doi: 10.1016/j.neulet.2013.01.003

Huang, Y. Z., Edwards, M. J., Rounis, E., Bhatia, K. P., and Rothwell, J. C. (2005). Theta burst stimulation of the human motor cortex. Neuron 45, 201-206. doi: 10.1016/j.neuron.2004.12.033

Huang, Z. J., Kirkwood, A., Pizzorusso, T., Porciatti, V., Morales, B., Bear, M. F., et al. (1999). BDNF regulates the maturation of inhibition and the critical period of plasticity in mouse visual cortex. Cell 98, 739-755. doi: 10.1016/s00928674(00)81509-3

Imbrosci, B., Neitz, A., and Mittmann, T. (2014). Focal cortical lesions induce bidirectional changes in the excitability of fast spiking and non fast spiking cortical interneurons. PLoS One 9:e111105. doi: 10.1371/journal.pone. 0111105

Jefferis, J. M., Connor, A. J., and Clarke, M. P. (2015). Amblyopia. BMJ 351:h5811. doi: 10.1136/bmj.h5811

Jiao, Y., Zhang, Z., Zhang, C., Wang, X., Sakata, K., Lu, B., et al. (2011). A key mechanism underlying sensory experience-dependent maturation of neocortical GABAergic circuits in vivo. Proc. Natl. Acad. Sci. U S A 108, 12131-12136. doi: 10.1073/pnas.1105296108

Karabanov, A., Ziemann, U., Hamada, M., George, M. S., Quartarone, A., Classen, J., et al. (2015). Consensus paper: probing homeostatic plasticity of human cortex with non-invasive transcranial brain stimulation. Brain Stimul. 8, 993-1006. doi: 10.1016/j.brs.2015.06.017

Kawaguchi, Y., and Kubota, Y. (1998). Neurochemical features and synaptic connections of large physiologically-identified GABAergic cells in the rat frontal cortex. Neuroscience 85, 677-701. doi: 10.1016/s0306-4522(97) 00685-4

Kawaguchi, Y., and Kondo, S. (2002). Parvalbumin, somatostatin and cholecystokinin as chemical markers form specific GABAergic interneuron types in the rat frontal cortex. J. Neurocytol. 31, 277-287. doi: 10. 1023/A:1024126110356

Kim, S., Stephenson, M. C., Morris, P. G., and Jackson, S. R. (2014). tDCS-induced alterations in GABA concentration within primary motor cortex predict motor learning and motor memory: a $7 \mathrm{~T}$ magnetic resonance spectroscopy study. Neuroimage 99C, 237-243. doi: 10.1016/j.neuroimage.2014.05.070

Knable, M. B., Barci, B. M., Bartko, J. J., Webster, M. J., and Torrey, E. F. (2002). Molecular abnormalities in the major psychiatric illnesses: classification and regression tree (CRT) analysis of post-mortem prefrontal markers. Mol. Psychiatry 7, 392-404. doi: 10.1038/sj.mp.4001034

Köppe, G., Brückner, G., Brauer, K., Härtig, W., and Bigl, V. (1997). Developmental patterns of proteoglycan-containing extracellular matrix in perineuronal nets and neuropil of the postnatal rat brain. Cell Tissue Res. 288, 33-41. doi: 10.1007/s004410050790

Kuhlman, S. J., Olivas, N. D., Tring, E., Ikrar, T., Xu, X., and Trachtenberg, J. T. (2013). A disinhibitory microcircuit initiates critical-period plasticity in the visual cortex. Nature 501, 543-546. doi: 10.1038/nature12485

Lefaucheur, J. P., André-Obadia, N., Antal, A., Ayache, S. S., Baeken, C., Benninger, D. H., et al. (2014). Evidence-based guidelines on the therapeutic use of repetitive transcranial magnetic stimulation (rTMS). Clin. Neurophysiol. 125, 2150-2206. doi: 10.1016/j.clinph.2014.05.021

Letzkus, J. J., Wolff, S. B., and Lüthi, A. (2015). Disinhibition, a circuit mechanism for associative learning and memory. Neuron 88, 264-276. doi: 10.1016/j. neuron.2015.09.024 
Lewis, D. A., Hashimoto, T., and Volk, D. W. (2005). Cortical inhibitory neurons and schizophrenia. Nat. Rev. Neurosci. 6, 312-324. doi: 10.1038/ nrn 1648

Maffei, A., Nataraj, K., Nelson, S., and Turrigiano, G. (2006). Potentiation of cortical inhibition by visual deprivation. Nature 443, 81-84. doi: 10 . 1038/nature05079

Maffei, A., Nelson, S., and Turrigiano, G. (2004). Selective reconfiguration of layer 4 visual cortical circuitry by visual deprivation. Nat. Neurosci. 7, 1353-1359. doi: $10.1038 / \mathrm{nn} 1351$

Markram, H., Toledo-Rodriguez, M., Wang, Y., Gupta, A., Silberberg, G., and $\mathrm{Wu}$, C. (2004). Interneurons of the neocortical inhibitory system. Nat. Rev. Neurosci. 5, 793-807. doi: 10.1038/nrn1519

Mauney, S. A., Athanas, K. M., Pantazopoulos, H., Shaskan, N., Passeri, E., Berretta, S., et al. (2013). Developmental pattern of perineuronal nets in the human prefrontal cortex and their deficit in schizophrenia. Biol. Psychiatry 74, 427-435. doi: 10.1016/j.biopsych.2013.05.007

Maya Vetencourt, J. F., Sale, A., Viegi, A., Baroncelli, L., De Pasquale, R., O'Leary, O. F., et al. (2008). The antidepressant fluoxetine restores plasticity in the adult visual cortex. Science 320, 385-388. doi: 10.1126/science.11 50516

Mix, A., Benali, A., Eysel, U. T., and Funke, K. (2010). Continuous and intermittent transcranial magnetic theta burst stimulation modify tactile learning performance and cortical protein expression in the rat differently. Eur. J. Neurosci. 32, 1575-1586. doi: 10.1111/j.1460-9568.2010. 07425.x

Mix, A., Benali, A., and Funke, K. (2014). Strain differences in the effect of rTMS on cortical expression of calcium-binding proteins in rats. Exp. Brain Res. 232, 435-442. doi: 10.1007/s00221-013-3751-6

Mix, A., Hoppenrath, K., and Funke, K. (2015). Reduction in cortical parvalbumin expression due to intermittent theta-burst stimulation correlates with maturation of the perineuronal nets in young rats. Dev. Neurobiol. 75, 1-11. doi: 10.1002/dneu.22205

Nahmani, M., and Turrigiano, G. G. (2014). Adult cortical plasticity following injury: recapitulation of critical period mechanisms? Neuroscience 283, 4-16. doi: 10.1016/j.neuroscience.2014.04.029

Nettekoven, C., Volz, L. J., Kutscha, M., Pool, E. M., Rehme, A. K., Eickhoff, S. B., et al. (2014). Dose-dependent effects of theta burst rTMS on cortical excitability and resting-state connectivity of the human motor system. J. Neurosci. 34, 6849-6859. doi: 10.1523/JNEUROSCI.4993-13.2014

Nettekoven, C., Volz, L. J., Leimbach, M., Pool, E. M., Rehme, A. K., Eickhoff, S. B., et al. (2015). Inter-individual variability in cortical excitability and motor network connectivity following multiple blocks of rTMS. Neuroimage 118, 209-218. doi: 10.1016/j.neuroimage.2015.06.004

Orduz, D., Bischop, D. P., Schwaller, B., Schiffmann, S. N., and Gall, D. (2013). Parvalbumin tunes spike-timing and efferent short-term plasticity in striatal fast spiking interneurons. J. Physiol. 591, 3215-3232. doi: 10.1113/jphysiol. 2012.250795

Pedapati, E. V., Gilbert, D. L., Horn, P. S., Huddleston, D. A., Laue, C. S., Shahana, N., et al. (2015). Effect of $30 \mathrm{~Hz}$ theta burst transcranial magnetic stimulation on the primary motor cortex in children and adolescents. Front. Hum. Neurosci. 9:91. doi: 10.3389/fnhum.2015.00091

Pizzorusso, T., Fagiolini, M., Gianfranceschi, L., Porciatti, V., and Maffei, L. (2000). Role of neurotrophins in the development and plasticity of the visual system: experiments on dark rearing. Int. J. Psychophysiol. 35, 189-196. doi: 10. 1016/s0167-8760(99)00053-7

Rogasch, N. C., Dartnall, T. J., Cirillo, J., Nordstrom, M. A., and Semmler, J. G. (2009). Corticomotor plasticity and learning of a ballistic thumb training task are diminished in older adults. J. Appl. Physiol. (1985) 107, 1874-1883. doi: 10. 1152/japplphysiol.00443.2009

Rogasch, N. C., Daskalakis, Z. J., and Fitzgerald, P. B. (2014). Cortical inhibition, excitation and connectivity in schizophrenia: a review of insights from transcranial magnetic stimulation. Schizophr. Bull. 40, 685-696. doi: 10 1093/schbul/sbt078

Sale, A., Berardi, N., Spolidoro, M., Baroncelli, L., and Maffei, L. (2010). GABAergic inhibition in visual cortical plasticity. Front. Cell. Neurosci. 4:10. doi: $10.3389 /$ fncel.2010.00010

Selemon, L. D., and Zecevic, N. (2015). Schizophrenia: a tale of two critical periods for prefrontal cortical development. Transl. Psychiatry 5:e623. doi: 10.1038/tp. 2015.115

Southwell, D. G., Froemke, R. C., Alvarez-Buylla, A., Stryker, M. P., and Gandhi, S. P. (2010). Cortical plasticity induced by inhibitory neuron transplantation. Science 327, 1145-1148. doi: 10.1126/science.1183962

Suttkus, A., Morawski, M., and Arendt, T. (2016). Protective properties of neural extracellular matrix. Mol. Neurobiol. 53, 73-82. doi: 10.1007/s12035014-8990-4

Taylor, S. F., and Tso, I. F. (2015). GABA abnormalities in schizophrenia: a methodological review of in vivo studies. Schizophr. Res. 167, 84-90. doi: 10. 1016/j.schres.2014.10.011

Thickbroom, G. W. (2007). Transcranial magnetic stimulation and synaptic plasticity: experimental framework and human models. Exp. Brain Res. 180, 583-593. doi: 10.1007/s00221-007-0991-3

Thimm, A., and Funke, K. (2015). Multiple blocks of intermittent and continuous theta-burst stimulation applied via TMS differently affect sensory responses in rat barrel cortex. J. Physiol. 593, 967-985. doi: 10.1113/jphysiol.2014.282467

Todd, G., Kimber, T. E., Ridding, M. C., and Semmler, J. G. (2010). Reduced motor cortex plasticity following inhibitory rTMS in older adults. Clin. Neurophysiol. 121, 441-447. doi: 10.1016/j.clinph.2009.11.089

Toyoizumi, T., Miyamoto, H., Yazaki-Sugiyama, Y., Atapour, N., Hensch, T. K., and Miller, K. D. (2013). A theory of the transition to critical period plasticity: inhibition selectively suppresses spontaneous activity. Neuron 80, 51-63. doi: 10.1016/j.neuron.2013.07.022

Trippe, J., Mix, A., Aydin-Abidin, S., Funke, K., and Benali, A. (2009). Thetaburst and conventional low-frequency rTMS differentially affect GABAergic neurotransmission in the rat cortex. Exp. Brain Res. 199, 411-421. doi: 10. 1007/s00221-009-1961-8

Tsien, R. Y. (2013). Very long-term memories may be stored in the pattern of holes in the perineuronal net. Proc. Natl. Acad. Sci. U S A 110, 12456-12461. doi: 10. 1073/pnas.1310158110

Uematsu, M., Hirai, Y., Karube, F., Ebihara, S., Kato, M., Abe, K., et al. (2008). Quantitative chemical composition of cortical GABAergic neurons revealed in transgenic venus-expressing rats. Cereb. Cortex 18, 315-330. doi: 10. 1093/cercor/bhm056

Volz, L. J., Benali, A., Mix, A., Neubacher, U., and Funke, K. (2013). Dosedependence of changes in cortical protein expression induced with repeated transcranial magnetic theta-burst stimulation in the rat. Brain Stimul. 6, 598-606. doi: 10.1016/j.brs.2013.01.008

Wegner, F., Härtig, W., Bringmann, A., Grosche, J., Wohlfarth, K., Zuschratter, W., et al. (2003). Diffuse perineuronal nets and modified pyramidal cells immunoreactive for glutamate and the $\mathrm{GABA}_{\mathrm{A}}$ receptor $\alpha 1$ subunit form a unique entity in rat cerebral cortex. Exp. Neurol. 184, 705-714. doi: 10.1016/s0014-4886(03)00313-3

Conflict of Interest Statement: The authors declare that the research was conducted in the absence of any commercial or financial relationships that could be construed as a potential conflict of interest.

Copyright (C) 2016 Hoppenrath, Härtig and Funke. This is an open-access article distributed under the terms of the Creative Commons Attribution License (CC BY). The use, distribution and reproduction in other forums is permitted, provided the original author(s) or licensor are credited and that the original publication in this journal is cited, in accordance with accepted academic practice. No use, distribution or reproduction is permitted which does not comply with these terms. 